\title{
The Effect of Acute Aerobical Exercise on Arterial Blood Oxygen Saturation of Athletes
}

\author{
Hüseyin Eroğlu ${ }^{1}$, Bülent Okyaz ${ }^{1}$, Ünal Türkçapar ${ }^{1}$ \\ ${ }^{1}$ Kahramanmaraş Sutcu İmam University, School of Physical Education and Sports, Turkey \\ Correspondence: Hüseyin Eroğlu, Kahramanmaraş Sutcu İmam University, School of Physical Education and Sports, \\ Turkey.
}

Received: August 20, 2018

doi:10.11114/jets.v6i9a.3562
Accepted: August 27, $2018 \quad$ Online Published: August 29, 2018

URL: https://doi.org/10.11114/jets.v6i9a.3562

\begin{abstract}
The aim of this study was to investigate the effect of acute aerobic exercise on arterial blood hemoglobin oxygen saturation in athletes.36 healthy male athletes participated voluntarily with the age $(20.9 \pm 1.6 \mathrm{yrs})$, weight $(69.8 \pm 5.5$ $\mathrm{kg}$ ) and height $(169.6 \pm 3.7 \mathrm{~cm})$, who studied at school of physical education and practiced 90 minutes of exercise 6 days a week,. This study was conducted with the approval of Ethics Committee of Health Sciences Institute with session date specified in article of Ethics Committee, dated in 13.09.2017.The heights, body weights and $\mathrm{VO}_{2}$ max values of participants were determined by $\mathrm{VO}_{2}$ max shuttle run test once, pre- and post-shuttle run heart rates and oxygen saturations were determined by pulse oximetry. The statistical analysis of data was made in SPSS 21.0 for windows package program. The normality test of data was done by Kolmogorov-Smirnov test, and it was found that data was not normally distributed. The Wilcoxon test, a nonparametric test, was used to determine for difference between pre-test and post-test. The significance value was taken at level 0.01.As a result of statistical analyses, it was determined that there was a statistically significant difference between oxygen saturations and heart rates of participants before and after exercise. In conclusion, it can be said that acute aerobic exercise can reduce oxygen saturation.
\end{abstract}

Keywords: oxygen saturation, acute aerobic exercise, athlete

\section{Introduction}

None of body stresses can be as much as or close to heavy exercise stress. Indeed, some of heavy exercises can easily become lethal when they are continued for a long time. Therefore, major problem in sports physiology is extent to which stress can be applied to body mechanisms. An example would be: in a person with the highest fever, body metabolism increases by about 100 percent near death. Nevertheless, an athlete's body metabolism may rise over 2000 percent in marathon race (Guyton \& Hall, 1996). This may lead to many physiological changes in the organism.

The study of physiological effects of exercise, which has numerous benefits for human health, is the subject of sports physiology. Sports physiology deals with the physiological aspects of exercise and sports medicine, how body functionally responds to exercise, adaptation of body to short and long exercise, and physiological basis of this adaptation. In addition to physiological responses given by human body to exercise and adaptation mechanisms, sports physiology also deals with creation of individual-specific exercise prescription and determination of an athlete's performance with cardio-pulmonary and anaerobic exercise tests (Cakir, 2009).

When four of hemoglobin groups are bound to oxygen, hemoglobin molocule is said to be completely saturated. The whole hemoglobin may not be completely saturated. The amount of oxygen transport capacity used is expressed as saturation percent of hemoglobin and is called $\mathrm{SbO}_{2} \%$. The saturation percentage is calculated as follows (Plowman \& Smith, 2003; Tiryaki, 2002).

$$
\text { The } \mathrm{SbO}_{2} \%=\frac{\text { oksijenlebirlesenhemoglobin }}{\text { oksijenlebirklsemesigerekenhemoglobinkapasitesi }} \times 100
$$

$\mathrm{SaO}_{2} \%$ and $\mathrm{SvO}_{2} \%$ symbols can be used to differentiate percentage of blood saturation in arteries and veins respectively, yet $\mathrm{Sb}$ means "not specific to blood". The saturation percentage mainly depends upon partial oxygen pressure. The saturation percentage of arterial blood in a $\mathrm{PO}_{2}$ of $95 \mathrm{mmHg}$ is $97 \%$. Since $\mathrm{PO}_{2}$ is $40 \mathrm{mmHg}$ in normal venous blood, $\mathrm{SbO}_{2}$ is determined as $75 \%$. (PLOWMAN \& SMITH, 2003). 


\section{$H b O 2=H b \times 1.34 \times S b O 2$}

In this equation, hemoglobin level of course varies from individual to individual. The physiological oxygen binding capacity is constant $1.34 \mathrm{mLO}_{2} \mathrm{gmBb}^{-1}$ and saturation percentage of hemoglobin will vary between arterial and venous blood, and rest and exercise conditions (Plowman \& Smith, 2003; Tiryaki, 2002).

Oxygen is substantially carried in blood bound to hemoglobin. A little part of it is in dissolved form. The amount of oxygen transported bound to hemoglobin is known as oxygen saturation $\left(\mathrm{SpO}_{2}\right)$. It is possible to consider maximal oxygen $\left(\mathrm{MaxVO}_{2}\right)$ intake among decisive factors that uplift the sportive success during long-term and high-tempo physical activity. The ability to use oxygen, one of key criteria to determine success especially during physical activities, in which aerobic metabolism is forced maximum, actually expresses ability of mitochondria to function in musculoskeletal cells. The high level of $\mathrm{MaxVO}_{2}$, determinant of aerobic capacity, allows athletes to exercise longer under homeostatic conditions. It is known that there are six important steps in determination of how much of oxygen in atmosphere air transported from alveoli to musculoskeletal mitochondria can be used during physical activity.

- Taking of oxygen into lungs by alveolar ventilation,

- Transition of oxygen to alveo-capillary membrane with diffusion,

- Binding of oxygen to hemoglobin,

- Arrival of oxygen to capillaries at arterial blood and tissue level,

- Transition of oxygen to mitochondria with diffusion at capillary level,

-Use of oxygen in oxidative phosphorylation and production of ATP (Ozdal et al., 2014).

Oxygen saturation measurement with pulse oximeter is important in presence of abnormal respiratory rate or bluish skin color change. Hypoxia is a state or condition in which oxygen saturation is below 95\% (Erhman et al., 2018).

When blood $\mathrm{PCO}_{2}$ increases in oxygen-hemoglobin dissociation curve, oxygen-bound hemoglobin rate is observed to raise gradually. This is called saturation percentage of hemoglobin. Since $\mathrm{PO}_{2}$ in arterial blood is about $95 \mathrm{mmHg}$, we can observe through dissociation curve that oxygen saturation of arterial blood is generally $97 \%$. On the other hand, $\mathrm{PO}_{2}$ in venous blood carried from tissues is about $40 \mathrm{mmHg}$ and hemoglobin saturation is about 75\% (Guyton \& Hall, 1996).

When $\mathrm{PO}_{2}$ and $\mathrm{PH}$ decrease and temperature rises, hemoglobin releases oxygen. Each of these conditions may reflect an increase local oxygen need. They metabolically increase the oxygen release in active tissues. Hemoglobin is usually saturated with about $98 \%$ oxygen. This is a much higher oxygen capacity than our bodies require, so oxygen carrying capacity of blood rarely limits the performance in healthy individuals (Wilmore et al., 2008; Powers \& Howley, 1990).

The effect of exercise that has many benefits for human health on circulation and respiratory system has been known. How oxygen saturation of hemoglobin in arterial blood changes among sedentary people which can be seen in relevant literature. However, effect of acute aerobic exercise on oxygen saturation of hemoglobin in arterial blood has been wondered as an original subject. This study attempted to investigate the effect of acute aerobic exercise on oxygen saturation of hemoglobin in arterial blood in athletes.

\section{Method}

\subsection{Study Group}

36 healthy male athletes with mean age of $20.9 \pm 1.6$ years, mean body weight of $69.8 \pm 5.5 \mathrm{~kg}$ and mean height of $169.6 \pm 3.7 \mathrm{~cm}$, who study at school of physical education and sports with 90 minutes of exercise 6 days a week, participated voluntarily in this study.

\subsection{Study Design}

This study was carried out in Sutcu Imam University, Institute of Health Sciences, Department of Physical Education and Sports. This study was conducted with approval of Ethics Committee of Health Sciences Institute with the session date specified in article of Ethics Committee, dated in 13.09.2017.

The participants of study were informed about the context and aim of study. Age, height, body weight, pre-exercise heart rate (PREHR), post-exercise heart rate (POEHR) and maximum oxygen use $\left(\mathrm{MaxVO}_{2}\right)$ ) data were used as descriptive parameters. The shuttle run test was used as acute aerobic exercise. Pre- and post-shuttle run heart rate counts and oxygen saturations were measured twice. The subjects participated in shuttle test three by three.

Body weight was measured by a scale with a sensitivity of $0.1 \mathrm{~kg}$ and a metal rod on this scale, while height was measured with a digital height gauge. The subjects participated in measurements only with their shorts. The measurement was taken with bare feet, head upright, while soles were flat on the scale, knees were tight, heels were adjacent and body was in the upright position. 


\subsection{Shuttle Run Protocol}

The subjects were taken in run test as groups of 3 people. They start running between two lines drawn 20 meters far away from each other with a whistle sound recorded previously according to a certain protocol. The subjects were asked to reach other line before next whistle (one foot should pass the line). At the beginning, length of whistle sounds is kept long, and since these are warm-up tours, subjects did not have to warm up before starting test. As time progresses, time between whistle sounds are gradually shortened and subjects have to run faster and faster. The subject, who could not reach opposite line two times successively before whistle sound, was considered not to have completed the test. Then, with the help of a specially prepared chart for this test, $\mathrm{VO}_{2}$ max values $(\mathrm{ml} / \mathrm{kg} / \mathrm{min})$ corresponding to level that each subject has to leave test were calculated indirectly.

\section{Measuring instruments}

-A gym that can form a 20-meter lane.

- Adhesive tape for lanes and turning lines.

- Cassette player

- A tape with the pre-recorded protocol.

- Follow-up chart for level and repetition.

A level form must be available for the evaluation of the subjects in the test. When every $20 \mathrm{~m}$ line was passed, the form was marked. At the end of test, marks taken by athlete were calculated and $\mathrm{VO}^{2}$ max value of subject was calculated in $\mathrm{ml} / \mathrm{kg} / \mathrm{min}$ through the evaluation chart (Gunay et al., 2006).

\subsection{Oxygen Saturation Measurement}

Continuous monitorization of arterial oxygen in anesthesia and intensive care patients was very important in determining a possible hypoxaemia. Normally, $98 \%$ of the oxygen in the blood was bound to hemoglobin (Hb) and $2 \%$ was found in free state in the plasma. Heart rate and oxygen saturation were determined by a pulse oximeter (Spirolab III, Medical International Research). Pulse oximeter measures the percentage of hemoglobin-bound oxygen saturation $(\mathrm{SaO} 2)$ in the arterial blood non-invasively and measured value was defined as $\mathrm{SpO}_{2}$. Pulse oximeter consists of two basic units, a microprocessor-equipped monitor and a peripheral probe. The monitor is part that displays arterial oxygen saturation $\left(\mathrm{SpO}_{2}\right)$, pulse wave pattern and arterial pulse rate on screen (Altug \& Gonenci, 2003).

\subsection{Evaluation of the Data}

The statistical analysis of obtained data was made in the SPSS 21.0 for windows package program. The normality test of data was done by Kolmogorov-Smirnov test, and it was found that data was not normally distributed. The arithmetic mean and standard deviation values of obtained data were determined. The Wilcoxon test, a nonparametric test, was used to determine difference between pre-test and post-test. The significance value was taken as 0.01 .

\section{Results}

36 volunteer male athletes participated in this study. The minimum, maximum, and arithmetic mean and standard deviations of the age, body weight (BW), height, maximum oxygen consumption, $\left(\mathrm{VO}_{2}\right.$ max), pre-exercise $\mathrm{SpO}_{2}$, post-exercise $\mathrm{SpO}_{2}$, pre-exercise heart rate (PREHR) and post-exercise heart rate (POEHR) of athletes are presented in Table 1.

Table1. The mean of some values of groups

\begin{tabular}{lccc}
\hline \multicolumn{1}{c}{ Variables } & Min & Max & $\overline{\boldsymbol{x}}_{ \pm}$sd \\
\hline Age $($ years $)$ & 19.0 & 24.0 & $20.9+1.6$ \\
\hline $\mathrm{BW}(\mathrm{kg})$ & 60.0 & 76.0 & $69.8 \pm 5.5$ \\
\hline Height $(\mathrm{cm})$ & 164.0 & 175.0 & $169.6 \pm 3.7$ \\
\hline $\mathrm{VO}_{2} \mathrm{max}(\mathrm{ml} / \mathrm{kg} / \mathrm{min})$ & 35.1 & 50.8 & $41.2 \pm 5.1$ \\
\hline Pre-exercise $\mathrm{SpO}_{2}(\%)$ & 95.0 & 99.0 & $97.3 \pm 1.3$ \\
\hline Post-exercise $\mathrm{SpO}_{2}(\%)$ & 92.0 & 98.0 & $96.2 \pm 2.2$ \\
\hline PREHR (beat $/ \mathrm{min})$ & 62.0 & 94.0 & $80.4 \pm 9.1$ \\
\hline POEHR (beats/min) & 157.0 & 191.0 & $178.4 \pm 11.1$ \\
\hline
\end{tabular}


Table 2. Non-parametric Wilcoxon test results between pre-exercise and post-exercise values of saturation and heart rate of group participated

\begin{tabular}{|c|c|c|c|c|c|c|}
\hline & RANKS & $\mathrm{N}$ & S.O & TS & $\mathrm{z}$ & $\mathrm{p}$ \\
\hline \multirow{4}{*}{$\mathrm{POE} \mathrm{SpO}_{2}-\mathrm{PRE} \mathrm{SpO}_{2}$} & Negative ranks & 15 & 9.80 & 147.00 & \multirow{4}{*}{$-2.695 *$} & \multirow{4}{*}{0.007} \\
\hline & Positive ranks & 3 & 8.00 & 24.00 & & \\
\hline & Equal & 18 & & & & \\
\hline & Total & 36 & & & & \\
\hline \multirow{4}{*}{ POEHR-PREHR } & Negative ranks & 0 & .00 & .00 & \multirow{4}{*}{$-5.238 *$} & \multirow{4}{*}{0.000} \\
\hline & Positive ranks & 36 & 18.50 & 666.00 & & \\
\hline & Equal & 0 & & & & \\
\hline & Total & 36 & & & & \\
\hline
\end{tabular}

*p $<$ 0.01, POESpO 2 :Post-exercise $\mathrm{SpO}_{2}, \mathrm{PRESpO}_{2}$ : Pre-exercise $\mathrm{SpO}_{2}$, POEHR: Post-exercise heart rate, PREHR: Pre-exercise heart rate

As Table 2 shows, there is a significant difference $(\mathrm{p}<0.01)$ between pre-exercise and post-exercise saturation and heart rate values of participants. The aforementioned difference in saturation value was in favor of pre-test. In other words, a significant decrease has been found in saturation values of athletes after acute exercise. The difference in heart rate values was in favor of post-test. This means that heart rates of athletes increased after acute exercise.

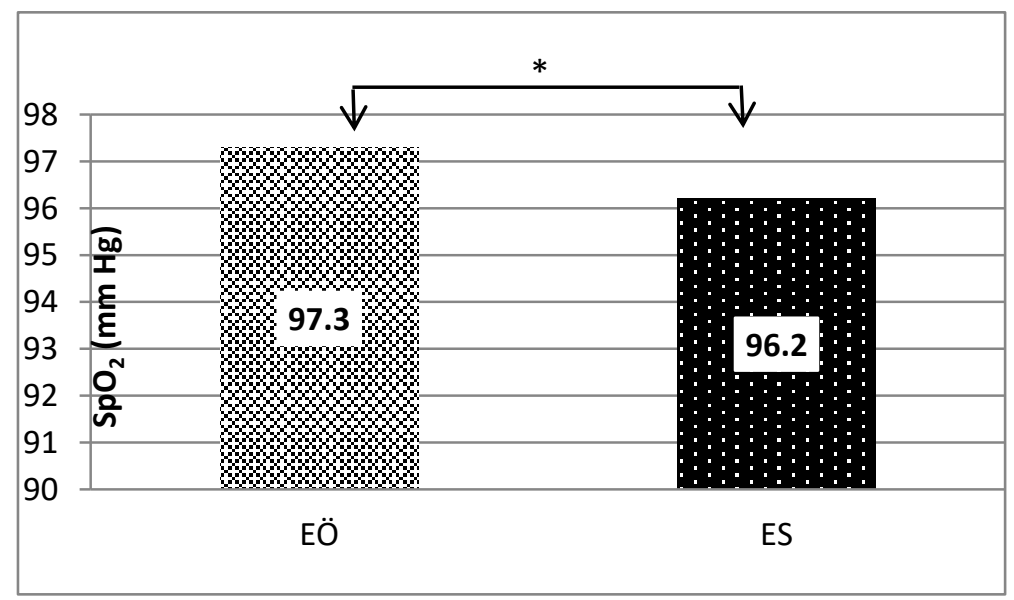

Chart 1. Pre-exercise and Post-exercise $\mathrm{Spo}_{2}$ Values

$* \mathrm{P}<0.01$

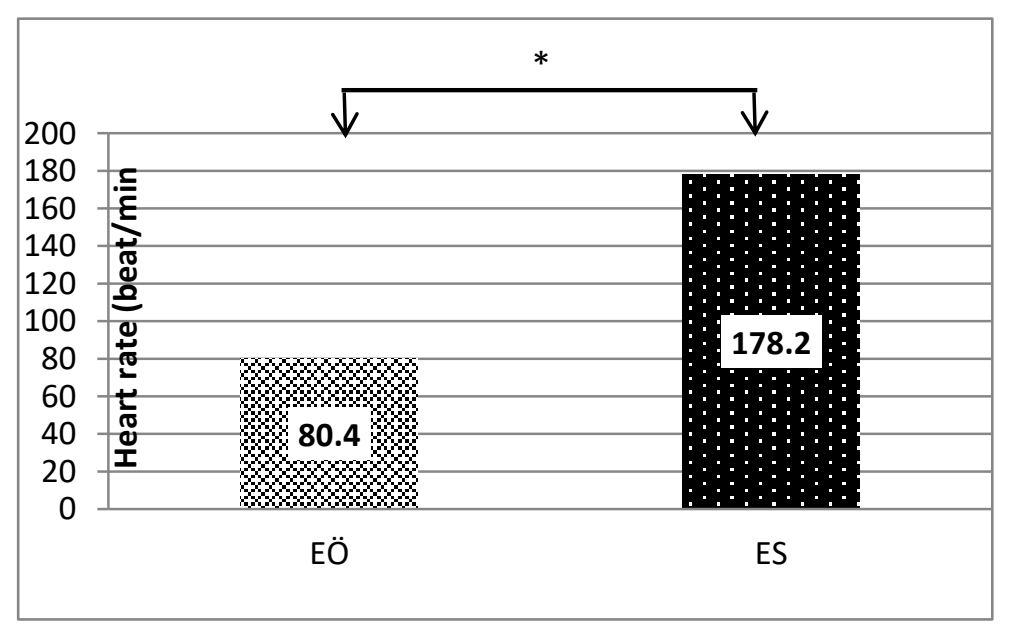

Chart 2. Pre-exercise and Post-exercise Heart Rate Values 


\section{Discussion and Conclusion}

The aim of this study is to investigate the effect of acute aerobic exercise on arterial blood hemoglobin oxygen saturation in athletes. The main results of study were that oxygen saturation of participants decreased after exercise, whereas heart rate values increased after exercise.

The hemoglobin oxygen dissociation curve is sigmoidal curve that shows relationship between partial oxygen pressure and hemoglobin oxygen saturation in blood. During exercise, carbon dioxide production increases, lactic acid builds up, blood $\mathrm{Ph}$ increases; all these shift curve to right. In other words, hemoglobin oxygen saturation becomes lower despite the same partial oxygen pressure during exercise. In other words, oxygen need increases. Normally, there is $15 \mathrm{~g}$ hemoglobin in $100 \mathrm{ml}$ blood of an adult. This amount of hemoglobin is found with $19.5 \mathrm{ml}$ oxygen bound to itself in arterial blood. This amount of oxygen ensures that hemoglobin in arterial blood is $97 \%$ saturated in terms of oxygen. The amount of dissolved oxygen in arterial blood is about $0.3 \mathrm{ml}$ in $100 \mathrm{ml}$ blood. As it is seen, majority of oxygen delivered to blood in lungs is transported bound to hemoglobin. When blood in arteries arrives in capillaries at tissue level, a certain amount of oxygen is released to be used by cells. So, amount of oxygen bound to hemoglobin in $100 \mathrm{ml}$ blood is reduced to $15.1 \mathrm{ml}$ and the amount of dissolved oxygen is reduced to $0.1 \mathrm{ml}$. These last two values belong to venous blood. Because after arterial blood passes through capillaries, it passes to vascular system. The oxygen saturation of hemoglobin of blood that passed to veins is reduced to $75 \%$. As is known, this is because of arterial blood releases of some oxygen for use of cells at capillary level (Ozdal et al., 2014). The oxygen saturation of arterial blood hemoglobin is vital for patients, sedentary or athletic individuals.

According to the results of this study, it is seen that acute aerobic exercise significantly decreased oxygen saturation in arterial blood $(\mathrm{p}<0.01)$ (Table 2). According to a study, an 8-week aerobic exercise has been found to have a positive effect on oxygen saturation of arterial blood hemoglobin in athletes and sedentary individuals (Ozdal et al., 2014).

In a study, it was observed that the effects of hypoxia on tissue oxygenation varied between working muscles during incremental exercise, and that tissue deoxygenation caused by hypoxia was exacerbated by faster working rates in vastus lateralis, but not occurred in medial gastrocnemius (Oswa et al., 2017).

In the study conducted on sport persons who perform ultra-endurance mountain race, it has been reported that there was no significant difference between pre-race (oxygen saturation: 97.36 $\pm 1.62 \%$ ) and post-race (oxygen saturation: $96.20 \pm 1.75 \%$ ) values, but post-race oxygen saturation decreased significantly (Belinchon et al., 2018).

In the study of "Investigation of Acute Effects of Training Mask Use in Maximum Aerobic Activity", which was conducted on football players, it was found that oxygen saturation decreasrdafter exercise (Ozel \& Ozer, 2017).

In another study, it was found that $\mathrm{SPO}_{2}$ saturation of Ankara Baglum Sports Club players decreasrd little by little at 10th, 20th, 30th and 40th minute of competition, while the $\mathrm{SPO}_{2}$ saturation of Isparta Iyas Youth and Sports club players raised at beginning, 10th, 20th, 30th, 40th minute of competition (Bagis \& Kumartasli, 2017).

In a study conducted on 117 patients, it was found that oxygen saturation decreasrd after aerobic exercise (Talvar et al., 2018).

In another study conducted on patients (patients without cystic fibrosis), it was found that oxygen saturation decreasrdafter the 6-min walk test (HSIEH, et al., 2017).

When relevant literature is reviewed, it is reported that acute chronic exercise reduces oxygen saturation and desaturation may occur during exercise (Demir \& Kucukoglu, 2010). The results of this study are supported by relevant literature.

In conclusion, we can say that hemoglobin oxygen saturation becomes lower despite the same partial oxygen pressure during exercise, as supported by the relevant literature. In other words, oxygen need increases. Because of that, it can be said that acute aerobic exercise reduces oxygen saturation.

\section{References}

Altug, M. E., \& Gonenci, R. (2003). Monitorization of Arterial Oxygenation with Pulse Oximetry. Veterinary Surgery Journal, 9(3-4), 58-62.

Bagis, Y. E., \& Kumartasli, M. (2017). Investigating the heart rate and oxygen saturation values of u13 category footballers at competition occasion who stand in different Uphill cities. Journal of Human Sciences, 14(2), 1975-1982. https://doi.org/10.14687/jhs.v14i2.4133

Belinchon-deMiguel, P., \& Clemente-Suarez, V. J. (2018). Psychophysiological, Body Composition, Biomechanical and Autonomic Modulation Analysis Procedures in an Ultraendurance Mountain Race. Journal of Medical Systems, 42, 32-37. https://doi.org/10.1007/s10916-017-0889-y 
Cakir, O. K. (2009). Sports Physiology and Clinical Expansion. Clinical Development, 22(3), 1-4.

Demir, R., \& Kucukoglu, M. S. (2010). Evaluation of exercise capacity in pulmonary arterial hypertension. Arch Turk Society Cardiology, 38(8), 580-588.

Erhman, J. K., Gordon, P. M., Visich, P. S., \& Keteyian, S. J. (2018). Clinical Exercise Physiology. (H. Arikan N, N. Ergun, A. R. Ozdincler, \& B. U. Tugay, Çev.) Istanbul: Istanbul Medical Health Publishing.

Gunay, M., Tamer, K., \& Cicioglu, I. H. (2006). Sports Physiology and Performance Measurement. Ankara: Gazi University Publication.

Guyton, A. C., \& Hall, J. H. (1996). Textbook of Medical Physiology, Istanbul: Nobel Publication.

Hsieh, M. H., Fang, Y. F., Chung, F. T., Lee, C. S., Chang, Y. C., Liu, Y. Z., et al. (2017). Distance-saturation product of the 6-minute walk test predicts mortality of patients with non-cystic fibrosis bronchiectasis. J. Thorac. Dis., 9(9), 3168-3176. https://doi.org/10.21037/jtd.2017.08.53

Osawa, T., Arimitsu, T., \& Takahashi, H. (2017). Hypoxia affects tissue oxygenation differently in the thigh and calf muscles during incremental running. Eur. J. Appl. Physiol., 117, $2057-2064$. https://doi.org/10.1007/s00421-017-3696-8

OzdalL, M., Daglioglu, O., Demir, T., \& Ozkul, N. (2014). Effect of Aerobic Trainning on Oxygen Saturation of Arterial Hemoglobin. Journal of Sports and Performance Researches, 5(1), 27-34.

Ozel, M. S., \& Ozer, M. K. (2017). Evaluation of the Acute Effects of Using Maximum Aerobic Activity Training Mask. IÜ Journal of Sports Sciences, 7(1), 1303-1014.

Plowman, S. A., \& Smith, D. L. (2003). Exercise Physiology for Health, Fitness, and Performance (Second Edition b.). San Francisco/ USA: Benjamin Cummings.

Powers, S. K., \& Howeley, E. T. (1990). Exercise PhysiologyY and Application to Fitness and Performance (Second Ed b.). Iowa: WCB Brown and Benchmark .

Talvar, S., Kumar, M. V., Sreenivas, V., Gupta, V. P., Choudhary, S. K., \& Airan, B. (2018). Exercise performance after univentricular palliation. Annals of Pediatric Cardiology, 11(1), 40-47. https://doi.org/10.4103/apc.APC_43_17

Tiryaki, S. G. (2002). Exercise and Sports Physiology. Bolu: ATA Publication.

Wilmore, J. H., Costill, D. L., \& Kenney, W. L. (2008). Physiology of Sport and Exercise (Fourth Ed. b.). USA: Human Kinetics.

\section{Copyrights}

Copyright for this article is retained by the author(s), with first publication rights granted to the journal.

This is an open-access article distributed under the terms and conditions of the Creative Commons Attribution license which permits unrestricted use, distribution, and reproduction in any medium, provided the original work is properly cited. 